Check for updates

The BMJ

Cite this as: $B M J 2020 ; 371: \mathrm{m} 4490$ http://dx.doi.org/10.1136/bmj.m4490 Published: 23 November 2020

\section{Caring for colleagues during the pandemic: Deepa Janga}

\section{Deepa Janga, consultant obstetrician and gynaecologist, talks to Marika Davies about being caught off guard by the pandemic and the importance of caring for colleagues}

\section{Marika Davies}

When Deepa Janga moved to the UK in 2005, she planned to complete her membership examinations and then return to India. But she fell in love with the NHS and found she couldn't leave.

"Where I come from, you can't imagine that everything, like cancer treatment, is the same for everyone," she says. "The concept that you can have anything and everything free for everyone is unique, very few countries in the world have something like this."

Janga grew up surrounded by an extended family of doctors. She always knew she wanted to study medicine, and graduated from Osmania Medical College in Hyderabad, India, in 1995.

She decided to be an obstetrician and gynaecologist during her time as a house officer. "Initially it was just because of the happiness around the specialty. It's so gratifying," she says. "But then you realise there's so much to it and you can branch out into many sub-specialties."

After moving to the UK, Janga completed her obstetrics and gynaecology training in London and became a consultant at the North Middlesex University Hospital NHS Trust in 2013.

Janga has been the Royal College of Obstetricians and Gynaecologists' college tutor for her trust since 2017 and was voted trainer of the year in her region in 2019. She believes in the mantra "pass it on," which she learnt early in her career. "Fantastic teachers and doctors go out of their way to train," she says.

As a trainer Janga's approach is to listen and try to remember how she felt when she was a trainee. "The best thing is to sit and listen, and to understand their perspective," she says.

Janga is worried by the current attrition and burnout rates among trainees and reminds her juniors to look out for themselves and their colleagues at work. "If someone has had a bad day, we must make sure we give some time to listen to them," she says.

The North Middlesex Hospital was one of the first to be affected by the covid-19 pandemic, and Janga's department cared for the first mother and baby who tested positive for coronavirus.

"However much you train, it was completely unexpected, it came like a surge," she recalls. "But there was a lot of camaraderie, we looked after our colleagues and worked together."

One difficulty was the shortage of staff because of sickness, and Janga was responsible for producing a new rota at short notice. "It was a huge challenge to our workforce," she says. "Everybody rose to that challenge and agreed to work more, whatever their life situations were."

As Janga and her colleagues face the second wave of covid-19, she is optimistic about measures put in place by her trust, such as treatment protocols, screening, risk assessments, and support for staff wellbeing. "There was a lot of anxiety among staff during the first wave-the fear of the unknown," she recalls. "We were caught off guard then. I hope we'll be in a slightly better position this time.”

\section{Nominated by Ishita Mishra}

"A gem of a person, Miss Janga has been with me in my most difficult times since I started my first job in the UK in 2017 at North Middlesex Hospital. She has been supportive, inspiring, and the most enthusiastic college tutor I have come across. She believed in me when I had lost faith in myself, and I have not let her down since that day."

Ishita Mishra is a specialty trainee year 5 in obstetrics and gynaecology at Royal Oldham Hospital, Greater Manchester, UK 